\title{
Mancha de mirotécio em algodoeiro causada por Myrothecium roridum.
}

\author{
Maurício Conrado Meyer ${ }^{1}$, Juliano César da Silva ${ }^{2}$, Gerliane Lorena Maia ${ }^{2}$, \\ César Júnior Bueno ${ }^{3,4}$, Nilton Luiz de Souza ${ }^{3}$
}

${ }^{1}$ Embrapa Soja, Caixa Postal 131, CEP 65800-000, Balsas, MA, e-mail: mauricio@embrapabalsas.com.br; ${ }^{2}$ Bolsista do CNPq; ${ }^{3}$ UNESP-FCA de Botucatu, SP, e-mail: niltonsouza@fca.unesp.br; ${ }^{4}$ Bolsista FAPESP.

Autor para correspondência: Maurício C. Meyer

Data de chegada: 27/05/2004. Aceito para publicação em: 10/10/2005.

\begin{abstract}
Meyer, M.C., Silva, J.C. da, Maia, G.L., Bueno, C.J., Souza, N.L. Myrothecium leaf spot of cotton caused by Myrothecium roridum. Summa Phytopathologica, v.32, n.4, p.390-393, 2006.

Myrothecium leaf spot caused by Myrothecium roridum Tode ex Fr. was observed on cotton fields in Maranhão State, Brazil, causing yield reduction of up to $60 \%$. Disease symptoms are lesions with concentric necrotic rings, with salient structures (sporodochia) irregularly distributed. Symptoms were observed on petioles, bracts, leaves and bolls of cotton cultivars Deltapine Acala 90, Fibermax 966 and Sure Grow 821. The pathogen was isolated and cultivated on potato-dextrose-agar (PDA) medium. The pathogenicity was evaluated on detached healthy bolls from cotton cv. Fibermax 966 (R6 vegetative stage), previously disinfested. Thirteen isolates of $M$. roridum were tested, which included

8 from cotton and 5 from soybean. Fungal structures were evaluated by using light microscope with ocular micrometer. The isolates infected cotton bolls and the MA-75 was the most aggressive strain. In average lesion diameter is $1,3 \mathrm{~cm}$ long at 7 days after inoculation, and $2,7 \mathrm{~cm}$ at 14 days. They also formed sporodochia concentrically disposed on PDA. Conidia are hyalines to dilute olivaceous, single-celled, abundantly produced in a dark green to black mass. Spores from cotton isolates are $5,1 \mu \mathrm{m} \times 1,5 \mu \mathrm{m}$ in size, and from soybean isolates are $5,8 \mu \mathrm{m} \times 1,5 \mu \mathrm{m}$. This is the first report of Myrothecium leaf spot in Brazilian cotton fields.
\end{abstract}

Key-words: fungus, Gossypium hirsutum, first report, disease description.

\section{RESUMO}

Meyer, M.C., Silva, J.C. da, Maia, G.L., Bueno, C.J., Souza, N.L. Mancha de mirotécio em algodoeiro causada por Myrothecium roridum. Summa Phytopathologica, v.32, n.4, p.390-393, 2006.

A mancha de mirotécio causada por Myrothecium roridum Tode ex Fr. foi observada em lavouras de algodão no sul do Maranhão, causando reduções de produtividade de até $60 \%$. Os sintomas da doença são lesões necróticas, circulares, com estruturas salientes, os esporodóquios, de distribuição irregular. Foram observadas lesões nos pecíolos, brácteas, folhas e maçãs de algodoeiro cv. Deltapine Acala 90, Fibermax 966 e Sure Grow 821. O isolamento do fungo foi realizado em meio de cultura batata-dextrose-ágar (BDA). O teste de patogenicidade foi realizado em maçãs sadias, destacadas de algodoeiro cv. Fibermax 966, no estádio vegetativo R6, previamente desinfestadas. Foram testados 13 isolados de $M$. roridum, oito provenientes de algodão e cinco de soja. Avaliações das estruturas fúngicas foram realizadas com auxílio de microscópio óptico equipado com um micrômetro ocular. Os isolados causaram infecções em maçãs de algodão e destacou-se como mais agressivo o MA-75, proveniente de algodão, apresentando diâmetro médio de lesão de $1,3 \mathrm{~cm}$, aos sete DAI e $2,7 \mathrm{~cm}$ aos 14 DAI. Todos os isolados formaram esporodóquios dispostos concenticamente em meio BDA. Os conídios são unicelulares, hialinos a oliváceos, abundantemente produzidos em massa verde-oliva a preta. Os conídios de isolados provenientes de algodão mediram, em média, $5,1 \mu \mathrm{m} \times 1,5 \mu \mathrm{m}$, e os obtidos de soja, $5,8 \mu \mathrm{m} \times$ $1,5 \mu \mathrm{m}$. Estes resultados relatam a ocorrência da mancha de mirotécio, causada por $M$. roridum, em lavouras comerciais de algodão no Brasil.

Palavras-chave adicionais: fungo, Gossypium hirsutum, nova doença, descrição. 
Tabela 1. Identificação e procedência dos isolados de Myrothecium roridum.

\begin{tabular}{cccccc}
\hline Isolado & Hospedeiro & Cultivar & Local da coleta & Material de isolamento & Data de isolamento \\
\hline MA-20 & Soja & BRS Sambaíba & Riachão, MA & Folha & $31 / 01 / 03$ \\
MA-21 & Soja & BRS Pati & Balsas, MA & Folha & $27 / 03 / 03$ \\
MA-22 & Soja & BRS Sambaíba & Riachão, MA & Folha & $27 / 03 / 03$ \\
MA-67 & Algodão & Sure Grow 821 & Tasso Fragoso, MA & Folha & $02 / 03 / 04$ \\
MA-72 & Algodão & Deltapine Acala 90 & Riachão, MA & Bráctea & $10 / 03 / 04$ \\
MA-73 & Soja & BRS Sambaíba & Riachão, MA & Folha & $10 / 03 / 04$ \\
MA-74 & Algodão & Deltapine Acala 90 & Riachão, MA & Folha & $10 / 03 / 04$ \\
MA-75 & Algodão & Sure Grow 821 & Tasso Fragoso, MA & Folha & $11 / 03 / 04$ \\
MA-76 & Algodão & Delta Pine 10 & Tasso Fragoso, MA & Maçã & $11 / 03 / 04$ \\
MA-77 & Soja & BRS Sambaíba & Tasso Fragoso, MA & Folha & $11 / 03 / 04$ \\
MA-82 & Algodão & Deltapine Acala 90 & Tasso Fragoso, MA & Folha & $21 / 03 / 04$ \\
MA-83 & Algodão & Sure Grow 821 & Tasso Fragoso, MA & Maçã & $24 / 03 / 04$ \\
MA-84 & Algodão & Deltapine Acala 90 & Tasso Fragoso, MA & Maçã & $24 / 03 / 04$ \\
\hline
\end{tabular}

Tabela 2. Diâmetro da lesão causada por Myrothecium roridum em maçãs destacadas de algodoeiro cv. Fibermax 966.

\begin{tabular}{cccc}
\hline Isolado & Hospedeiro & \multicolumn{2}{c}{ Diâmetro da lesão $(\mathrm{cm})^{*}$} \\
& & 7 dias & 14 dias \\
\hline MA-20 & Soja & 0 & 0 \\
MA-21 & Soja & 0 & 0 \\
MA-22 & Soja & 0 & 0 \\
MA-67 & Algodão & 0,97 & 2,42 \\
MA-72 & Algodão & 0,57 & 1,30 \\
MA-73 & Soja & 0,57 & 1,76 \\
MA-74 & Algodão & 0,67 & 1,60 \\
MA-75 & Algodão & 1,32 & 2,67 \\
MA-76 & Algodão & 0,65 & 0,73 \\
MA-77 & Soja & 0,72 & 1,80 \\
MA-82 & Algodão & 0,50 & 1,90 \\
MA-83 & Algodão & 1,00 & 1,70 \\
MA-84 & Algodão & 0,76 & 1,50 \\
Testemunha & - & 0 & 0 \\
\hline
\end{tabular}

* Média de quatro repetições.

A mancha de mirotécio causada por Myrothecium roridum Tode ex Fr. na cultura do algodão, foi relatada pela primeira vez na Índia (3). Posteriormente, lesões nos pecíolos, brácteas e maçãs foram descritas por Srivastava \& Singh (6) e Raut et al. (5). No Brasil a doença já foi descrita nas culturas da soja (1) e acerola (4). O objetivo deste trabalho foi relatar a ocorrência da mancha de mirotécio na cultura do algodoeiro, em áreas de produção no sul do Maranhão.

A doença foi observada na safra 2003/2004, em áreas de produção de algodão, nos municípios de Tasso Fragoso e Riachão, MA. Lesões nos pecíolos, brácteas, folhas e maçãs foram verificadas em plantas de algodoeiro. Os sintomas da doença são lesões necróticas, circulares, de coloração vinho no início da formação em tecidos verdes, tornandose marrons a negras à medida que evoluem, formando esporodóquios irregularmente distribuídos (Figura 1 A, B, C, D, E).

$\mathrm{O}$ isolamento do fungo foi realizado em meio de cultura batatadextrose-ágar (BDA) e mantido em câmara incubadora tipo $\mathrm{BOD}$, à temperatura de $27^{\circ} \mathrm{C}$. Em aproximadamente sete dias a colônia do fungo ocupou toda a área do meio de cultura da placa e apresentou abundante formação de esporodóquios (Figura $1 \mathrm{~F}, \mathrm{~J}$ ).

Devido à capacidade do patógeno de infectar as estruturas 
Tabela 3. Tamanho de conídios de isolados de Myrothecium roridum provenientes de algodão e soja.

\begin{tabular}{|c|c|c|c|c|c|c|c|}
\hline \multirow{2}{*}{ Isolado } & \multirow{2}{*}{ Hospedeiro } & \multicolumn{3}{|c|}{ Comprimento de conídio $(\mu \mathrm{m})^{*}$} & \multicolumn{3}{|c|}{ Largura de conídio $(\mu \mathrm{m})^{*}$} \\
\hline & & mínimo & médio & máximo & mínimo & médio & máximo \\
\hline MA-67 & Algodão & 3,4 & 5,0 & 5,8 & 0,8 & 1,6 & 2,0 \\
\hline MA-72 & Algodão & 3,2 & 5,0 & 7,0 & 1,0 & 1,6 & 2,2 \\
\hline MA-84 & Algodão & 4,4 & 5,3 & 6,2 & 0,8 & 1,4 & 2,0 \\
\hline \multicolumn{2}{|c|}{ Média } & 3,7 & 5,1 & 6,3 & 0,9 & 1,5 & 2,1 \\
\hline \multirow{4}{*}{\multicolumn{2}{|c|}{$\begin{array}{l}\text { MA-73 } \\
\text { MA-77 } \\
\text { MA-06 } \\
\text { MA-07 }\end{array}$}} & 3,6 & 5,1 & 6,6 & 0,8 & 1,3 & 1,8 \\
\hline & & 4,6 & 6,1 & 7,6 & 1,2 & 1,7 & 2,6 \\
\hline & & 4,4 & 5,7 & 6,8 & 0,8 & 1,6 & 2,0 \\
\hline & & 4,8 & 6,4 & 8,4 & 1,0 & 1,6 & 2,4 \\
\hline \multicolumn{2}{|c|}{ Média } & 4,3 & 5,8 & 7,3 & 0,9 & 1,5 & 2,2 \\
\hline
\end{tabular}

* Média da medição de 20 conídios por isolado.

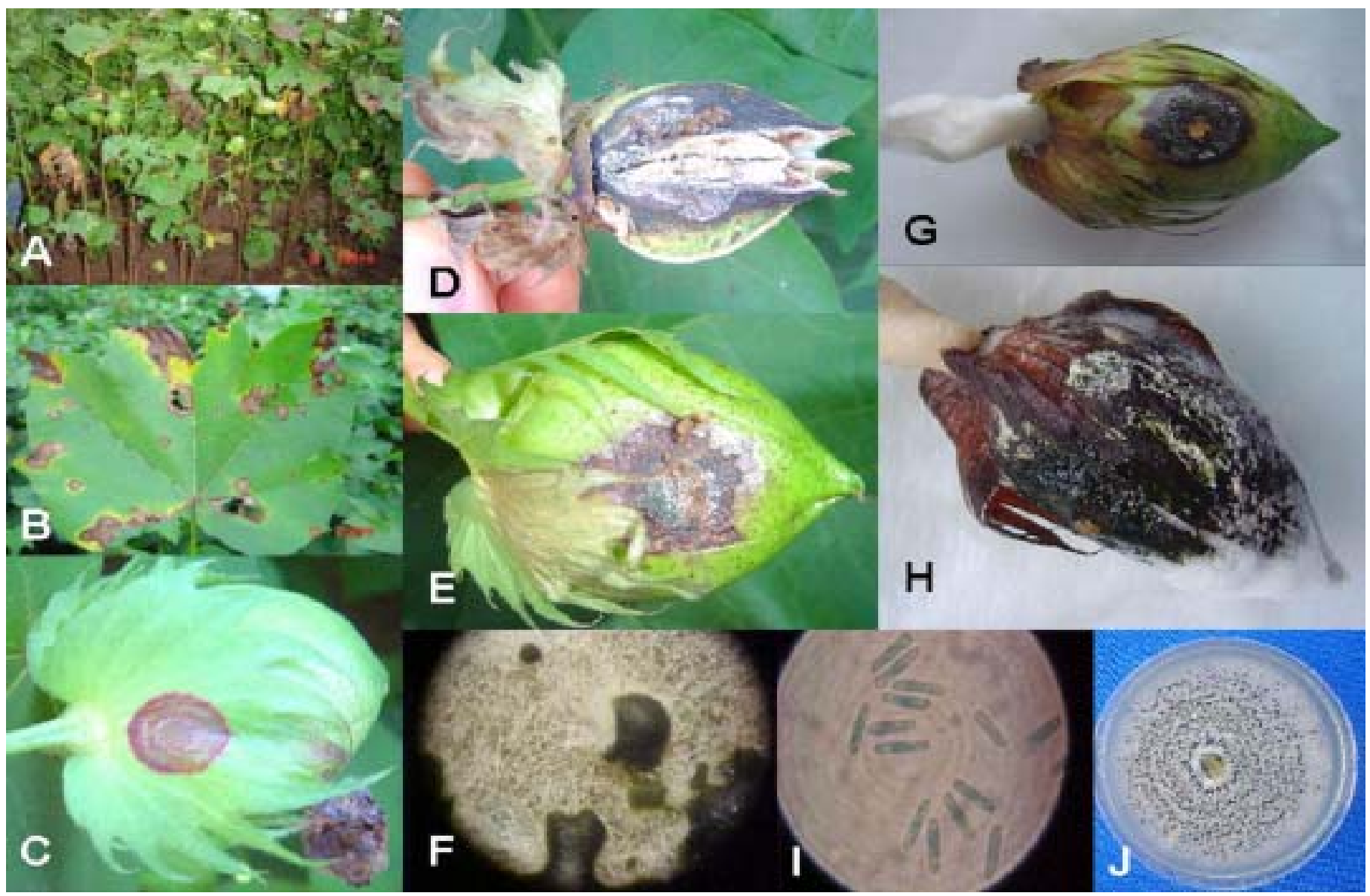

Figura 1 - Aspecto geral de plantas de algodoeiro com mancha de mirotécio (A). Sintomas foliares (B), nas brácteas (C) e maçãs (D e E). Esporodóquios de Myrothecium roridum visualizados sob microscópio estereoscópico, com 34X de aumento (F). Maçãs inoculadas com o isolado MA-75, aos 7 DAI (G) e 20 DAI (H). Conídios de M. roridum com aumento de 1000X (I). Aspecto de colônia de M. roridum em BDA (J). DAI= dias após inoculação.

reprodutivas da planta, causando danos diretos à produção, optou-se por avaliar a patogenicidade do fungo em maçãs de algodoeiro. Foram avaliados 13 isolados de $M$. roridum, oito provenientes de algodoeiro e cinco de soja (Tabela 1). A inoculação foi realizada em maçãs sadias de algodoeiro cv. Fibermax 966, no estádio vegetativo R6, desinfestadas por imersão em solução de hipoclorito de sódio a $1 \%$, durante um minuto e acondicionadas individualmente em caixas Gerbox, forradas com duas folhas de papel filtro umedecidas com água estéril. Foi colocado sobre as maçãs um disco de BDA de $5 \mathrm{~mm}$ de diâmetro, contendo estruturas do fungo. Maçãs não inoculadas com o patógeno foram mantidas nas mesmas condições como testemunhas. As maçãs foram incubadas em câmara BOD durante 14 dias a $27^{\circ} \mathrm{C}$, com fotoperíodo de 12 horas. A avaliação da patogenicidade dos isolados foi realizada por meio de medição do diâmetro da lesão, aos sete dias e 14 dias após a inoculação (Tabela 2). Foi realizado o reisolamento do fungo a partir de lesões 
características da doença.

Os sintomas de apodrecimento foram reproduzidos nos testes de avaliação de patogenicidade em maçãs destacadas (Figura $1 \mathrm{G}$, H). Os isolados MA-75 e MA-67 foram mais agressivos aos 14 dias após a inoculação. Os isolados MA-73 e MA-77, provenientes de soja, foram patogênicos tanto quanto os isolados de algodão. Entretanto, os isolados MA-20, MA-21 e MA-22, obtidos de soja, comportaram-se como não patogênicos, devido provavelmente às repicagens sucessivas em meio de cultura ou a fatores intrínsecos (Tabela 2).

Os conídios de três isolados de $M$. roridum, provenientes de algodoeiro e quatro de soja, foram analisados e medidos em microscópio óptico equipado com micrômetro ocular. Todos os isolados apresentaram esporos unicelulares, hialinos a oliváceos, com extremidades arredondadas e freqüentemente apresentando gutulações (Figura 1 I). Os isolados provenientes de algodão e soja apresentaram tamanhos médios de conídios de 5,1 (3,7-6,3) $\mu \mathrm{m} \mathrm{x}$ $1,5(0,9-2,1) \mu \mathrm{m}$ e $5,8(4,3-7,3) \mu \mathrm{m} \times 1,5(0,9-2,2) \mu \mathrm{m}$, respectivamente (Tabela 3 ). Este resultado concorda com os apresentados por Almeida et al. (1) para isolados obtidos de soja, medindo $5-7 \mu \mathrm{m} \times 1-2 \mu \mathrm{m}$. A descrição do fungo reporta tamanhos médios de conídios de $7,2 \mu \mathrm{m} \times 1,8 \mu \mathrm{m}$, utilizando como espécie tipo isolados de tomateiro (2).

Esses resultados relatam a ocorrência da mancha de mirotécio em áreas comerciais de produção de algodão, nos municípios de Tasso Fragoso e Riachão, MA, Brasil.

\section{REFERÊNCIAS BIBLIOGRÁFICAS}

1. Almeida, A.M.R.; Kaster, M.; Albuquerque, F.C. Ocorrência de Myrothecium roridum Tode ex Fr. em soja (Glycine max) (L.) Merrill) no Estado do Piauí. Fitopatologia Brasileira, Brasília, v. 5, p. 129-133, 1980.

2. Fitton, M.; Holliday, P. Myrothecium roridum. C.M.I. Description of Pathogenic Fungi and Bacteria n. 253. Commonwealth Mycological Institute, Ferry Lane, Kew, Surrey, England. 1970.

3. Munjal, R.L. A commonly occuring leaf spot disease caused by Myrothecium roridum Tode ex Fr. Indian Phytopathology, New Delhi, v. 13, p. 150-155, 1960.

4. Poltroniere, L.S.; Duarte, M.L.R.; Alfenas, A.C. Three new pathogens infecting antilles cherry in the State of Pará. Fitopatologia Brasileira, Brasília, v. 28, p.424-426, 2003.

5. Raut, J.G.; Holey, N.R.; Moghe, New Delhi, P. G. Ocurrence of Myrothecium leaf spot on cotton in Vidarbha. Indian Phytopathology, New Delhi, v. 33, p. 510-511, 1980.

6. Srivastava, M.P.; Singh, A. Myrothecium disease of cotton. Journal of Research - Haryana Agricultural University, Haryana, v. 3, p. 221-223, 1973. 